\title{
Assessing patient-centred care through direct observation of clinical encounters
}

\author{
Jennifer N Stojan, ${ }^{1}$ Michael A Clay, ${ }^{2}$ Monica L Lypson ${ }^{3,4}$
}

${ }^{1}$ Departments of Internal Medicine and Pediatrics and Communicable Diseases, University of Michigan, Ann Arbor, Michigan, USA ${ }^{2}$ Ann Arbor Veterans Affairs Healthcare System, and Department of Internal Medicine, University of Michigan, Ann Arbor, Michigan, United States

${ }^{3}$ Ann Arbor Veterans Affairs Healthcare System, Ann Arbor, Michigan, USA

${ }^{4}$ Departments of Internal Medicine and Learning Health Sciences, and Office of Graduate Medical Education, University of Michigan Medical School, Ann Arbor, Michigan, USA

\section{Correspondence to}

Monica L Lypson, Ann Arbor VA Healthcare System, Professor of Internal Medicine \& Learning Health Sciences, University of Michigan Medical School, 2215 Fuller Road \#11J, Ann Arbor, MI 48105, USA; mlypson@umich.edu

Received 3 September 2015 Accepted 15 September 2015 Published Online First 30 September 2015

\section{SLinked}

- http://dx.doi.org/10.1136/ bmjqs-2015-004283

- http://dx.doi.org/10.1136/ bmjqs-2015-004521

- http://dx.doi.org/10.1136/

bmjqs-2015-005008

CrossMark

To cite: Stojan JN, Clay MA, Lypson ML. BMJ Qual Saf 2016;25:135-137.
Patient-centred care, defined as respecting and responding to the needs and preferences of patients, empowering them to make decisions that best fit their individual needs, has been identified by the Institute of Medicine as an essential element of high-quality care. ${ }^{1}$ It can be thought of as respectfully involving the patient ${ }^{2}$ in a way that helps practitioners provide care that is concordant with their patients' values, needs and preferences while better enabling patients to actively provide input and participate in their healthcare. ${ }^{3}$ Patients are more satisfied with their care when they feel that healthcare providers are understanding their needs, carefully listening and clearly providing information ${ }^{4}$; in addition, patient-centred care has been found to be associated with improved patient outcomes. ${ }^{5}$ In order to provide exemplary patient-centred care, one needs well developed communication skills, especially in the realm of active listening and responding to patient cues. The importance of physicians mastering the art of patient-centred communication skills can be seen as a theme in the educational objectives of medical school curricula as well as in the competencies of the Accreditation Council for Graduate Medical Education. ${ }^{2}$

Approaches to evaluating patientcentred communication skills include patient surveys that assess satisfaction with a healthcare provider ${ }^{6}$ and direct observation. Training programmes employ standardised patients to directly observe communication skills such as with Objective Structured Clinical Examinations. ${ }^{7}$ Direct observation can also occur in real time or through videotaped or audiotaped real patient encounters. When using audiotaped encounters, the 'Content Coding for Contextualization of Care' or 4C method can be used to evaluate clinical care performance. ${ }^{8}$ With this method, audio recordings of patient-provider encounters are used to assess whether care planning has taken into account patients' contextual factors, individual needs or circumstances that are relevant to planning appropriate care. The coding takes into account whether or not there were clues of patient context relative to care, and if so, determines if the healthcare provider explored the context. If they did explore the context, the next step is to see if the patient provided confirmatory evidence of the contextual factors and whether the provider addressed the contextual factors in the care plan.

The paper by Schwartz et al ${ }^{9}$ identifies some success and opportunities for improvements in the area of contextualised care. The authors see patientcentred care as the 'provider elicitation and incorporation of patient contextual factors, individuating information which, is important to managing the patient's health'. Drawing from three datasets totalling 1392 patient-physician encounters and 96 client-health assistant telephone calls, this study used the 4C coding system to explore the impact of how the provider learned the contextual information by (1) probing (a provider behaviour that can be targeted for performance improvement) or (2) through spontaneous expression by the patient. They found patient contextual factors identified via probing were incorporated into the plan of care more frequently than those spontaneously revealed by patients $(68 \%$ vs $46 \%, 71 \%$ vs $54 \%$, and $93 \%$ vs $77 \%$, respectively). In summary, the data demonstrated that providers are more accepting of contextual factors that they are able to elicit by probing and more dismissive of those factors revealed in spontaneous conversation by the 
patient. ${ }^{9}$ Of note, these same authors in their early work using these data found that patient outcomes improved in significantly more cases when the physician had incorporated the patient's contextual information into the care plan than when the physician had not. ${ }^{10}$

A recent commentary noted that patient-centred care requires healthcare providers to not only elicit patients' wishes but also to recognise and respond to their needs and concerns. ${ }^{4}$ Notable in this statement is the 'respond to' action which is often under appreciated. From the Schwartz et al data, it would seem that the majority of providers minimised or disregarded what patients brought up on their own, which clearly is not in line with patient-centred communication. If patients care enough to spontaneously bring up issues on their own, they regard them as important. In bringing up issues, patients may want their providers to think about them, or at the very least listen and respond to them, if for no other reason than to validate their concerns and dispel any worries. By minimising or disregarding the issues raised by patients, providers miss an opportunity for patientcentred care. As Rollnick et $a l^{11}$ point out, practising patient-centred care is more than just 'being nice' to patients. It also involves listening, clarifying, reflecting and bridging gaps.

Interestingly, in the Schwartz et al study, health assistants were able to provide more contextualisation of care across factors, whether probed or spontaneously. Despite the small sample size, one has to wonder what training or experience is provided to health assistants that allows for their contextualisation at a higher level. One has to also wonder if the health assistants contextualise at a higher level because they are 'closer in proximity' potentially, socioeconomically, and educationally, or without professional distance from the patient compared with physicians, and therefore can better relate to them.

Although many recognise that communication skills are vital in becoming a skilled healthcare provider, few recognise the need to continue to learn and refine these skills. Healthcare providers strive to instil the value and importance of communication to their trainees. Students learn about communication in medical school curricula and their skills are tested in observed structured clinical examinations. Unfortunately, students are rarely given feedback on their communication skills in their clerkships when they are immersed in patient care. This lack of attention continues during their postgraduate training. ${ }^{12}$ This may be partially fuelled by faculty time constraints, but may also be due to lack of faculty development in the area of communication.

Ironically, although many physicians recognise the need for continuing medical education in the realm of medical knowledge, most physicians do not recognise the potential for improvement in their communication skills, believing that they already do this well. ${ }^{4}$ Rather than assume that they are proficient in communication skills, physicians should embrace continued growth in this area and participate in training strategies that have been identified for teaching communication skills to physicians. ${ }^{13}$ One such strategy is through direct observation of physician communication skills. This can be a powerful tool to employ, as through direct observation and feedback, one can be coached and corrected. Through the use of direct observation and evidence-based communication competencies, one can have a window into the doctor-patient relationship. With this method, physicians can participate in quality improvement projects as they relate to patient-centred care approaches/techniques and can be motivated to pursue excellence in patient-centred communication. ${ }^{14}$ In addition, the approach of direct observation and evaluation may also have the benefit of the Hawthorne effect, becoming even more powerful at changing physician communication behaviour than patient surveys. $^{6}$

Therefore, audiotaped (or videotaped) encounters such as those used in the Schwartz et al study could and should be used for the purposes of continuing education in communication skills. Perhaps if participants in the Schwartz et al study received feedback about their behaviour of not incorporating patient contextual clues, they would have been given the opportunity to self-reflect and correct their behaviour, therefore becoming more patient centred. One aspect not measured in the $4 \mathrm{C}$ method is how tone might affect the probing or spontaneity of the contextual factor. Johnson et $a l^{15}$ explored differences in the quality of medical visits among African American versus white patients. They looked at the overall communication process, the orientation of patient centeredness and the emotional tone. Physicians were more verbally dominant with African American patients than with white patients; they talked 43\% more than African American patients and only 24\% more than white patients. Physicians' affective tone was less positive during medical visits with African American patients than with white patients.

In summary, the paper by Schwartz et al provides another window into the conversations between healthcare providers and patients, with valuable insights into patient-centred care for providers and teachers of healthcare communication. Only direct observation (or recordings) of patient visits could have generated these data, underscoring the value of direct observation in medical education and quality improvement. We call on healthcare systems, accrediting bodies, and professional organisations to support, emphasise and even mandate continuous training and professional development through direct observation of the most common and complex procedure undertaken by healthcare providers-the medical interview. 
Acknowledgements We would like to thank Paula T. Ross, PhD for her coordination, support and editorial assistance.

Competing interests None declared.

Provenance and peer review Commissioned; internally peer reviewed.

\section{REFERENCES}

1 Institute of Medicine. Committee on Quality of Health Care in America. Crossing the quality chasm: a new health system for the 21st century. Washington DC: National Academy Press, 2001.

2 Boyle D, Dwinnell B, Platt F. Invite, listen, and summarize: a patient-centered communication technique. Acad Med 2005;80:29-32.

3 Gerteis M, Edgman-Levita S, Daley J, et al. Through the patient's eyes: understanding and promoting patientcentered care. San Francisco, CA: Jossey-Bass Publishers, 1993.

4 Levinson W. Patient-centred communication: a sophisticated procedure. BMJ Qual Saf 2011;20:823-5.

5 Griffin SJ, Kinmonth AL, Veltman MW, et al. Effect on health-related outcomes of interventions to alter the interaction between patients and practitioners: a systematic review of trials. Ann Fam Med 2004;2:595-608.

6 Fossli Jensen B, Dahl FA, Safran DG, et al. The ability of a behaviour-specific patient questionnaire to identify poorly performing doctors. BMJ Qual Saf 2011;20:885-93.

7 Stroud L, Vidyarthi AR. Assessing patient safety competencies using Objective Structured Clinical Exams: a new twist on an old tool. BMJ Qual Saf 2015;24:179-81.
8 Weiner SJ, Kelly B, Ashley N, et al. Content coding for contextualization of care: evaluating physician performance at patient-centered decision making. Med Decis Making 2014;34:97-106.

9 Schwartz A, Weiner SJ, Binns-Calvey A, et al. Providers contextualise care more often when they discover patient context by asking: a meta-analysis. BMJ Qual Saf 2016;25: 159-63.

10 Weiner SJ, Schwartz A, Sharma G, et al. Patient-centered decision making and health care outcomes: an observational study. Ann Intern Med 2013;158:573-9.

11 Rollnick S, Mason P, Butler C. Health behavior change-a guide for practitioners. Churchill Livingston, 1999.

12 Levinson W, Pizzo PA. Patient-physician communication: it's about time. JAMA 2011;305:1802-3.

13 Berkhof M, van Rijssen HJ, Schellart AJ, et al. Effective training strategies for teaching communication skills to physicians: an overview of systematic reviews. Patient Educ Couns 2011;84:152-62.

14 Henry SG, Holmboe ES, Frankel RM. Evidence-based competencies for improving communication skills in graduate medical education: a review with suggestions for implementation. Med Teach 2013;35: 395-403.

15 Johnson RL, Roter D, Powe NR, et al. Patient race/ ethnicity and quality of patient-physician communication during medical visits. Am J Public Health 2004;94: 2084-90. 